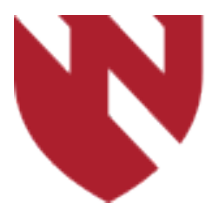

October 2021

\title{
Patient Safety Ward of Woe: Using Gamification to Reinforce Patient Safety at a Large Academic Hospital
}

\author{
Grant A. Turner \\ University of Nebraska Medical Center \\ Julie Fedderson \\ University of Nebraska Medical Center \\ Bethany Lowndes \\ University of Nebraska Medical Center
}

Tell us how you used this information in this short survey.

Follow this and additional works at: https://digitalcommons.unmc.edu/gmerj

Part of the Higher Education Commons, and the Medicine and Health Sciences Commons

\section{Recommended Citation}

Turner, G. A., Fedderson, J., , Lowndes, B. Patient Safety Ward of Woe: Using Gamification to Reinforce Patient Safety at a Large Academic Hospital. Graduate Medical Education Research Journal. 2021 Oct 04; 3(1). https://digitalcommons.unmc.edu/gmerj/vol3/iss1/30 


\section{Patient Safety Ward of Woe: Using Gamification to Reinforce Patient Safety at a Large Academic Hospital}

\section{Creative Commons License}

\section{c) (1)@ $\Theta$}

This work is licensed under a Creative Commons Attribution-Noncommercial-No Derivative Works 4.0 License. 
Conclusions: Our findings suggest

phenotypic and behavioral alterations

associated with chronic midazolam exposure, namely reduced body weight and head circumference, as well as increased obsessive compulsive and anxious behaviors in the midazolam group. Future directions for our ongoing study are to assess molecular and biochemical effects on synaptogenesis.

https://doi.org/10.32873/unmc.dc.gmerj.3.1.012

\section{Grant A. Turner ${ }^{1}$, Julie Fedderson², Bethany Lowndes ${ }^{3}$ \\ ${ }^{1}$ University of Nebraska Medical Center, College of Medicine, Department of Internal Medicine, Division of Pulmonology \\ ${ }^{2}$ University of Nebraska Medical Center, College of Medicine, Department of Internal Medicine \\ ${ }^{3}$ University of Nebraska Medical Center, College of Medicine, Department of Neurological Sciences}

Patient Safety Ward of Woe: Using Gamification to Reinforce Patient Safety at a Large Academic Hospital

Mentor: Julie Fedderson

Program: Internal Medicine

Type: Original Research

Background: Healthcare organizations have many priorities, including the education and reinforcement of patient safety and The Joint Commission National Patient Safety Goals (NPSGs). Patient safety escape rooms add gamification to educational programs, adding relevant skills in an enjoyable format. At our institution, all employees undergo patient safety training. We created the "Ward of Woe" to reinforce this training by incorporating errors that were clinical and non-clinical, common and uncommon, and related explicitly to NPSGs.
Methods: In March 2020, an escape room was created using already present materials. All employees were invited to the event. Before entering, the participant was given an SBAR containing information on the simulation. The room contained over 100 errors; each participant was asked to document five. Afterward, the participant was given a small prize. A survey to gather opinions was sent one week later.

Results: 147 participants participated in the event. $87 \%$ of participants felt the training was relevant to their job and $82 \%$ felt it helped them learn about patient safety; $38 \%$ thought it changed their opinion on patient safety. The percentage of clinical or nonclinical errors did not differ between types of participants.
Conclusions: We were able to take previously described patient safety escape rooms, incorporate NPSGs from The Joint Commission, and create a system-wide educational event. This inexpensive event was felt relevant and educational by participants and easily replicated and scaled to other healthcare organizations. Future interventions can work on making virtual offerings and determining the long-term effects of these interventions.

https://doi.org/10.32873/unmc.dc.gmerj.3.1.014

\section{Resident Perception of Respiratory Therapist Directed Asthma Protocol Weaning and the Impact on Education Simone Warrack¹, Nathaniel Goodrich¹, Lauren Maskin¹, Allison Ashford1, Kristy Carlson² ${ }^{1}$ University of Nebraska Medical Center, College of Medicine, Department of Pediatrics 'University of Nebraska Medical Center, College of Medicine, Department of Otolaryngology}

Mentor: Nathaniel Goodrich

Program: Pediatrics

Type: Original Report

Background: Children's Hospital and Medical Center has been utilizing an asthma exacerbation pathway in the inpatient setting for several years. In October 2019 respiratory therapist (RT)-led albuterol weaning was implemented. Though several studies have been published on RT-led weaning of albuterol treatments, the key metrics reported thus far have included cost, length of stay, imaging, and use of steroids. Other studies have analyzed the implementation of pathways but not RT-led weaning protocols on resident education. To our knowledge, our study is to the first to attempt to examine the impact of an RT-led weaning protocol on resident education.

Methods: Pediatric and Medicine-pediatric residents completed electronic anonymous surveys with subjective and objective questions to assess resident comfort and knowledge. Follow-up focus groups were conducted to allow for open dialogue regarding the RT-led weaning protocol.

Results: Fifty seven percent of residents responded to the survey. Most residents felt comfortable assessing and weaning asthmatics. The objective questions revealed that $57 \%$ of residents correctly calculated respiratory scores and a majority of residents could pinpoint when to wean or escalate treatment. Notably, $11 \%$ of residents participated in the focus groups.

Conclusions: Most residents felt comfortable caring for asthmatics and agreed that pathways or protocols support resident education. The residents indicated that hands-on learning was a large component of their education but expressed a need for team approach in asthma care. This study was limited by the fact that few participating residents had actual experience with RT-led albuterol weaning.

https://doi.org/10.32873/unmc.dc.gmerj.3.1.013 